\title{
Consumer Complaining Behavior: The Case of a South American Country, Chile
}

\author{
Fredy Valenzuela \\ University of New England, Australia, and \\ University of Talca, Chile \\ E-mail: fvalenzu@une.edu.au. \\ David Pearson \\ University of New England, Australia \\ E-Mail: dpearson@une.edu.au \\ Roger Epworth \\ University of New England, Australia \\ E-Mail: repworth@une.edu.au \\ Orlando Llanos \\ Universidad Católica de la Santísima Concepción, Chile. \\ E-Mail: ollanos@ucsc.cl \\ Sonia Vilches \\ Universidad Católica de la Santísima Concepción, Chile. \\ E-Mail: svilches@ucsc.cl
}

\begin{abstract}
Complaining behaviour is a topic that has not been studied much in South America. Considering this, the aim of this investigation was to determine the customers complaining behaviour of a South American country, Chile. To do so, a survey was done, which was applied to a random sample of 498 Chileans. Results show that Chileans do not consider complaining as a right, they have a regular opinion of the way companies are handling complaints, and that the product characteristics is the dimension that has the biggest influence on their complaining behaviour. In addition those Chilean consumers who have complained in the past have a more positive attitude toward complaining than those who have never done it.
\end{abstract}

Key Words: Complaining, Consumer Behaviour, South America, Chile 


\section{INTRODUCTION}

In an ideal world, when consumers are dissatisfied they would immediately speak up so firms would have the opportunity to respond immediately by improving the quality of their services. However, not many people complain, so firms do not know that they are incurring in a service failure. Based on this, it is evident that failure in management is not necessarily through having a high percentage of consumer complaints to deal with (Zairi, 2000), rather firms should encourage consumers to speak up every time they are dissatisfied (Barlow and Moller, 1996:26).

One aspect in which there is consensus among researchers is the fact that not all consumers engage in some of complaint action. In this line, Andreassen (2001) mentioned that the number of consumers who complain is lower that of those who do not complain. Chakrapani (1998:12) suggested that only $4 \%$ of dissatisfied consumers complain, and this is due to different reasons, which are: a) consumers might not know to whom to complain, b) negative experiences related to having their complaints handled poorly, and c) consumer belief that complaining is an exercise in futility because they will be either ignored or patronized. In general, these reasons can be categorized coming from two sources: company attitude toward responses to complaints and consumer attitude toward complaining. The latter is the personal tendency of dissatisfied costumers to seek compensation from the firm (Beardon and Mason, 1984).

Several studies have been done to cover different issues related to consumers complaining behaviour however a very important issue that has not been addressed in the literature is the situation of developing countries, and in particular South American countries. There are only few studies that focus on consumer complaining behaviour, such as Valenzuela (1999) and Valenzuela et al. (2002a; 2002b), but all them give only an overall picture of Chileans complaining behaviour, covering aspects such as percentage of consumers who complain and gender and social class differences. Due to this, firms in these countries have to use information gathered in a totally different setting to make decisions as to the design mechanisms for encouraging consumers to speak up every time they are dissatisfied with what have purchased.

Considering this, this study aims to gather information regarding Chilean consumers complaining behaviour.

\section{LITERATURE REVIEW}

Barlow and Moller (1996:43) presented the results of study done by the Case Western Reserve University, in which interviewed dissatisfied consumers fell into four clusters and were identified as voicers (37\%), passives (14\%), irates (21\%), and activists (28\%). Voicers will tell the company that something is wrong, passives will not say anything and will remain purchasing from their suppliers at least for a while, irates will not say a word to the firms but they will engage in negative word of mouth, and activists more than redress, they look for revenge.

Regarding the variables that influence consumers complaining behaviour, several studies have shown that there is a relationship between complaining and demographic variables, psychographic variables (e.g. consumer personality and attitude toward firms) and product characteristics.

Demographic variables have been subject of attention and different conclusions have been obtained by different researchers. For instance, Keng et al. (1995) and Heung and Lam (2003) concluded that female consumers are more inclined to complain, while Manikas and Shea (1997) findings show totally the opposite. Relative to the role of education, research has shown that 
there is a direct relationship between level of education and complaining (Beardon and Mason, 1984; Day and Lando, 1977; Heug and Lam, 2003; Jacoby and Jaccard, 1981; Morganosky and Buckely, 1986).

In relation to psychographic factors, such as personality and attitude, Davidow and Dacin (1997) concluded that these factors are the major reasons of complaint behaviour. In the same line, other researchers have concluded that consumers who complain are more social responsible and willing to take risks such as the risk of embarrassment when complaining (Fornell and Westbrook, 1979; Keng et al., 1995; Lau and Ng, 2001). If differences between complainers and non-complainers are considered, non-complainers considered that complaining was done by people with little else to do and it would be futile (Keng et al., 1995).

Concerning attitude toward firms, several researchers have concluded that there is a positive relationship between responsiveness and complaining (Keng et al., 1995; Lau and Ng, 2001; Richins and Verhage, 1985). Sometimes consumers are discouraged from speaking up by negative complaint handling procedures, such as simple apologies and nothing more, rejection (verbal or non verbal), promises that are not acted upon, no response at all, rude treatment, being passed on to someone else, employees who avoiding personal responsibility or consumer interviews that turn into interrogations (Barlow and Moller, 1996:59-61).

With regard to the relationship between product characteristics and complaining behaviour, Day and Lando (1977) and Keng et al. (1995) concluded that is more likely for consumer to complain if the product is not performing as promised and this situation can have a negative impact on their image of the firm. It was also demonstrated that there is a direct relationship between price and complaining behaviour, meaning that consumer will engage in complaining behaviour if the product they are dealing with is more expensive.

\section{METHODOLOGY}

The main method used in this study was a survey. To do so, a questionnaire was designed, which was in Spanish and had open-ended and close-ended questions. The first ones were used to allow respondents to give a description of the situation that provoked the complaint. Closeended questions were used to gather data related to the Chilean consumers complaining behaviour, which in this study was divided in four dimensions: a) Consumer Personality, b) Consumer Social Responsibility, c) Product Characteristics, and d) Attitude toward firms. To measure these dimensions, scale items used in other research were used, but with some small modifications to adapt them to the Chilean context (Keng et al., 1995; Phau and Puspita Sari, 2004). These scale items were translated to Spanish by the researcher, and the translation was checked by two Chilean Marketing Research Professors, so to ensure that the translation was appropriate. Table 1 show examples of scale items used in this investigation. 
Table 1 Example of Scales Items Used to Measure Consumer Attitude toward Complaining

\begin{tabular}{|l|l|}
\hline Dimension & \multicolumn{1}{|c|}{ Scale Item } \\
\hline Consumer Personality & I find it embarrassing to complain \\
\hline Consumer Social Responsibility & Complaining about an unsatisfactory product is my duty \\
\hline Product Characteristics & $\begin{array}{l}\text { The more frequently I have to use the product, the more likely I } \\
\text { am to complaint if it is faulty }\end{array}$ \\
\hline Attitude Toward Firms & Firms are usually willing to provide repairs for faulty products \\
\hline
\end{tabular}

Concerning sampling and because it is intended to get data related to complaint issues, it was key to interview people who have had a bad purchase experience, this means, they have been dissatisfied with what they bought. Due to this, the question 'have you ever been dissatisfied with the product/service you purchased?' was included in the questionnaire, and all people who answered 'no' were dropped from the study.

The exploratory research consisted in a survey that was applied to 498 Chileans. It also important to mention that from those 498 consumers, 98 or $20 \%$ indicated that they have never been dissatisfied with the product or service they got from a supplier. From the rest $(n=400), 317$ or $79 \%$ mentioned to have complained in the past (See Figure 1).

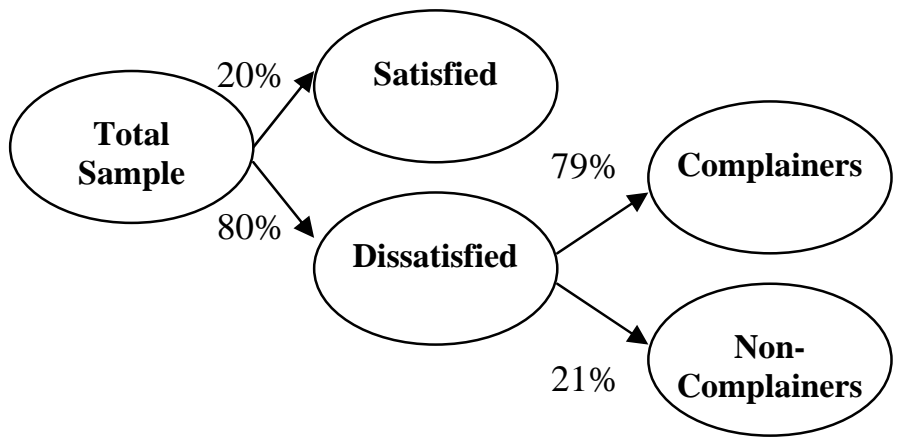

Figure 1 Sample Data Distribution

Regarding data analysis, several approaches were used in order to check validity and reliability. First factor analysis was done using Varimax Rotation. To check reliability of each factor Alfa Cronbachs were calculated. Then Confirmatory Factory analysis was done using AMOS 5.0

\section{MAIN FINDINGS}

Main finding were divided into four: a) Complaints per Industry, b) Consumer Complaining Behaviour Construct, c) Overall Results for each Consumers Complaining Behaviour Dimension, and d) Influence of a Series of Variables on Consumers Complaining Behaviour

\section{Complaints per Industry}

As can be seen in Table 2, the industry that got most complaints was the department store category with a $31.4 \%$ of all complaints followed by specialist stores with $30.5 \%$ of all complaints, supermarkets $10.2 \%$, telephone industry with $6.3 \%$, and bank industry with $5.7 \%$. 
Table 2 Complaints per Industry Type

\begin{tabular}{|l|c|}
\hline \multicolumn{1}{|c|}{ Industry } & Percentage \\
\hline Department Store & $31.4 \%$ \\
\hline Specialist Store & $30.5 \%$ \\
\hline Supermarkets & $10.2 \%$ \\
\hline Telephone & $6.3 \%$ \\
\hline Banks & $5.7 \%$ \\
\hline Transport & $3.8 \%$ \\
\hline Others & $12.1 \%$ \\
\hline
\end{tabular}

Regarding data analysis, this was divided into three types: 1) validity and reliability of the construct "Consumer Complaining Behaviour", 2) overall results for each dimension considered in this study, and 3) Influence of several variables (e.g. gender, social class, city and complainer or non complainer) on consumers complaining behaviour.

\section{Consumer Complaining Behaviour Construct}

Four factors resulted from factor analysis, each of them with three scale items. The lodging values of the scales items in their respective factor went from 0.60 to 0.80 . Regarding reliability, Alfa Cronbachs were not very high ranging from 0.57 and 0.65 . In relation to the total explained variance this was only 59\% (See Table 3).

Regarding the meaning of each factor, the first one represents the consumer's personality affecting complaining, the second one consumer's social responsibility, the third one is related to product characteristics affecting consumer complaining behaviour, and the last one to consumer's attitude toward the way firms handle complaints.

Table 3 Consumer Complaining Behaviour Construct: Factor Analysis

\begin{tabular}{|l|c|c|c|c|}
\hline & $\begin{array}{c}\text { Consumer } \\
\text { personality }\end{array}$ & $\begin{array}{c}\text { Consumer Social } \\
\text { Responsibility }\end{array}$ & $\begin{array}{c}\text { Product } \\
\text { characteristics }\end{array}$ & $\begin{array}{c}\text { Attitude toward } \\
\text { firms }\end{array}$ \\
\hline Consumer Personality 1 & 0.61 & & & \\
\hline Consumer Personality 2 & 0.78 & & & \\
\hline Consumer Personality 3 & 0.71 & & & \\
\hline Consumer Social Resp.1 & & 0.80 & & \\
\hline Consumer Social Resp.2 & & 0.75 & & \\
\hline Consumer Social Resp.3 & & 0.60 & & \\
\hline Product Characteristics 1 & & & 0.75 & \\
\hline Product Characteristics 2 & & & 0.79 & \\
\hline Product Characteristics 3 & & & & 0.71 \\
\hline Attitude toward firms 1 & & & & 0.80 \\
\hline Attitude toward firms 2 & & & & \\
\hline Attitude toward firms 3 & & & & \\
\hline Reliability & 0.57 & $14.6 \%$ & $14.5 \%$ & $14.2 \%$ \\
\hline Explained Variance & $15 \%$ & $29.6 \%$ & $44.3 \%$ & $58.5 \%$ \\
\hline Accumulate Variance & $15 \%$ & & & 0.75 \\
\hline
\end{tabular}


To further validate these dimensions, confirmatory factor analysis was done, using the software AMOS 5.0. The values of all goodness of fit indexes are very good (e.g. GFI, AGFI and CFI are above 0.9 and RMSEA below 0.8) confirming the existence of a multidimensional structure in the sample data. The values obtained in this analysis can be observed in Table 4

Table 4 Confirmatory Factor Analysis Goodness of Fit Indexes

\begin{tabular}{|l|c|}
\hline \multicolumn{1}{|c|}{ Goodness of fit Index } & Value \\
\hline GFI & 0.96 \\
\hline AGFI & 0.94 \\
\hline CFI & 0.92 \\
\hline RMSEA & $0.05[0.039-0.068]$ \\
\hline Chi-Square & 102.114 \\
\hline Degree of Freedom & 48 \\
\hline Chi-Square to Degree of Freedom ratio & 2.12 \\
\hline
\end{tabular}

\section{Overall Results for each Consumers Complaining Behaviour Dimension}

Regarding the four dimensions considered in this study, only one of them got a high mean, two of them were in the average and one of them got a very low score (See Table 5). The dimension 'product characteristics' got a high score, meaning that Chilean consumers complaining behaviour depends on the characteristics of the product. If the product is considered important for them it is very likely that they will complain. The dimension 'attitude toward firms' got a regular score, meaning that Chilean consumer believe that Chilean companies do not care for solving their complaints so it would be a wasted of time engage in a complaining behaviour. The dimension 'consumer personality' got also a regular score, meaning that Chilean consumers see themselves as passive people regarding complaining. Regarding the last dimension, consumers' social responsibility, this dimension got the lowest score, meaning that Chilean do not see complaining as a right or/and as an obligation.

Table 5 Chilean Consumer Complaining Behaviour Means

\begin{tabular}{|l|c|c|}
\hline & Mean & Standard Deviation \\
\hline Product Characteristics & 4.32 & 0.71 \\
\hline Consumers' Personality & 3.35 & 0.99 \\
\hline Attitude toward firms & 3.30 & 0.97 \\
\hline Consumers' Social Responsibility & 2.33 & 0.89 \\
\hline
\end{tabular}

Influence of a Series of Variables on Consumers Complaining Behaviour

In order to further understand the behaviour of Chilean consumers, several additional analyses were done with the aim of comparing the attitude score obtained by different variables, such as gender and type of complainer. The main findings are show next.

\section{Gender Differences}

The percentage of women and men who have complained to the supplier is very high, $78.4 \%$ and $80 \%$, respectively. The difference between these two percentages is not statically significant. It is important to mention that this result does not mean that every time that they are 
dissatisfied these consumers have complained, it is just saying that they have done it at least once.

Regarding the four dimensions considered in this study, the main results of this analysis can be seen in Table 6. In this Table is very clear that there is almost no difference in the answers of men and women. The only aspect that differs in the latter is the social responsibility aspect in where men scored higher than women, meaning that they are much more social responsible than women.

Table 6 Difference between Men and Women

\begin{tabular}{|l|c|c|}
\hline & Mean Difference & Significance \\
\hline Consumers' Social Responsibility & 0.350 & 0.000 \\
\hline Consumers' Personality & 0.001 & 0.875 \\
\hline Product Characteristics & -0.109 & 0.131 \\
\hline Attitude toward firms & -0.110 & 0.260 \\
\hline
\end{tabular}

\section{Social Class}

To determine if there is any difference among social class, ANOVA analysis was done, which shows no statistical difference among the attitude of consumers belonging to the low, medium and upper class (see Table 7).

This conclusion was further supported by the fact that there is no statistical difference in the percentages of consumers from upper, medium and low social classes who have complained at least once in the past. These percentages are $81 \%, 77 \%$ and $83 \%$, respectively.

Table 7 ANOVA for difference among Social Class

\begin{tabular}{|l|c|c|}
\hline & F & Significance \\
\hline Consumers' Personality & 0.197 & 0.821 \\
\hline Consumers' Social Responsibility & 0.950 & 0.388 \\
\hline Product Characteristics & 0.787 & 0.456 \\
\hline Attitude toward firms & 2.235 & 0.108 \\
\hline
\end{tabular}

\section{Complainers versus non Complainers}

In order to determine if there is any difference in the attitude regarding complaining of consumers who have complained in the past versus those who have never done it, mean differences were calculated for each of the four dimensions of the consumer complaining behavior. Results show statistical differences in the mean of three of the four dimensions, these being consumers' personality, consumers' social responsibility and the influence of the product characteristics. The only dimension that shows no significant difference is attitude toward firms, meaning that complainers and non complainers have a similar perception regarding the attitude that firms have for solving complaints. Table 8 shows the main results of this analysis. 
Table 8 Difference between Complainers and Non-Complainers

\begin{tabular}{|l|c|c|}
\hline & Mean Difference & Significance \\
\hline Consumers' Personality & +1.005 & 0.000 \\
\hline Consumers' Social Responsibility & +0.340 & 0.001 \\
\hline Product Characteristics & +0.411 & 0.000 \\
\hline Attitude toward firms & +0.001 & 0.916 \\
\hline
\end{tabular}

\section{CONCLUSIONS}

Several conclusions can be obtained from this study. The first one is the validity of the four dimensions to measure consumers complaining behavior. In this study results of the confirmatory factor analysis were excellent which further reaffirm the existence of this multidimensional structure.

Regarding Chileans' complaining behavior it was determined that there are several aspects that are negatively influencing their behavior. It seems that Chilean are more likely to complain when the product that is in involved in the complaint situation has attributes that are considered important for the consumer, such as, high price, long-term expectancy life, or a product that they use often.

In relation to the way firms are handling complaints Chilean consumers have a regular opinion of the willingness of these firms for handling their complaints in a proper way. This could imply that Chilean consumers may not be willing to speak up when they are dissatisfied with the product, because they will consider it a waste of time and energy.

The other dimensions considered in this study consumer personality shows also a medium score, meaning that Chilean feel some how embarrass when complaining, and if this characteristics is added to the fact that Chilean do not consider complaining as a right or social responsibility, it might lead to low rate of consumers complaints.

Relative to some variables that might influence the consumer complaining behavior, there is evidence that gender and social class are not relevant in this matter, which is different from those conclusions made in other research (Keng et al., 1995; Phau and Puspita, 2004).

The variable that shows a statistical difference in consumers complaining behavior is the type of complainer. Active complainers have a more positive attitude while passive or noncomplainers have a more negative attitude toward complaining. This result is in line with what was concluded by Chulmin et al. (2003) regarding that is more likely that consumers who have a more positive attitude toward complaining will engage in such a behavior.

All these conclusions have very important managerial implications. Firms that want to increase the number of consumers who complain when they are dissatisfied should:

a) Focus on consumers who are active complainers, who are not defined by gender of social class. The reason for this is because it would be more likely to achieve a greater impact from these consumers, because they have a positive attitude toward complaining. 
b) Have in place mechanisms for handling complaints otherwise the consumers will increase their negative perception regarding the attitude that firms have to solve complaints.

\section{LIMITATIONS}

The main limitation of this investigation is the ability to generalize its conclusions, mainly because all data were gathered only in two Chilean cities, and hence there is the opportunity for validation of its conclusions in other Chilean cities and other South American countries.

\section{REFERENCES}

Andreassen, T. W. (2001). From disgust to delight: Do customers hold a grudge? Journal of Service Research : JSR, 4(1), 39.

Barlow, J., \& Moller, C. (1996). A Complaint is a Gift. San Francisco: Berrett-Koehler Publishers.

Beardon, W., \& Mason, J. (1984). An investigation of influences on consumer complaint reports. In T. Kinnear (Ed.), Advances in Consumer Research (Vol. 11).

Chakrapani, C. (1998). How to Measure Service Quality \& Customer Satisfaction. Chicago: Amercian Marketing Association.

Chulmin, K., Sounghie, K., Subin, I., \& Changhoon, S. (2003). The effect of attitude and perception on consumer complaint intentions. Journal of Consumer Marketing, 20(4), 352371.

Davidow, M., \& Dacin, P. (1997). Understanding and influencing consumer complaint behaviour: improving organizational complaint management. Advances in Consumer Research, 24.

Day, R., \& Lando, E. (1977). Toward a theory of consumer complaint behaviour. In W. e. al. (Ed.), Consumer and Industrial Buying Behaviour. New York: North Holland.

Fornell, C., \& Westbrook, R. (1979). An exploratory study of assertiveness and consumer complaining behaviour. Advances in Consumer Research, 6, 105-114.

Heug, V., \& Lam, T. (2003). Customer complaint behaviour towards hotel restaurants services. International Journal of Contemporary Hospitality Management, 15(5), 283-289.

Jacoby, J., \& Jaccard, J. (1981). The sources, meanings and validity of consumer complaint behaviour: a psychological analysis. Journal of Retailing, 57(3), 4-24.

Keng, K., Richmond, D., \& Han, S. (1995). Determinants of consumer complaint behaviour: a study of Singapore consumers. Journal of International Consumer Marketing, 8(2), 59-76.

Lau, G., \& Ng, S. (2001). Individual and situational factors influencing negative work of mouth behaviour. Revue Canadienne des Sciences de l'Administration, 18(3), 163-178.

Manikas, P., \& Shea, L. (1997). Hotel complaint behaviour and resolution: a content analysis. Journal of Travel Research, 36(2), 68-73.

Morganosky, M., \& Buckely, H. (1986). Complaint behaviour: analysis by demographics, lifestyle and consumer values. Advances in Consumer Research, 14, 223-226.

Phau, I., \& Puspita, R. (2004). Engaging in complaint behaviour : An Indonesian perspective. Marketing Intelligence and Planning, 22(4), 407-426.

Richins, M., \& Verhage, V. (1985). Seeking redress for consumer dissatisfaction: the role of attitudes and situational factors. Journal of Consumer Policy, 18(1), 29-44. 
Valenzuela, F. (1999). Consumer Complaining Behavior: The Chilean Situation. Paper presented at the CLADEA, San Juan, Puerto Rico.

Valenzuela, F., Silva, R., \& Valdes, V. (2002a). Comparative Study of Chilean and German Consumers Profiles and Effects of an Ineffective Management of Complaining. Documents of Economy and Administration, 4, 16-18.

Valenzuela, F., Silva, R., \& Valdes, V. (2002b). Consumer Complaining Behavior: Comparative Study of Chilean and German Consumers. Panorama Socioeconomico, 24, 36-40.

Zairi, M. (2000). Managing Customer Dissatisfaction Through Effective Complaints Management Systems. The TQM Magazine, 12(5), 331-335. 